$\stackrel{\odot}{I I}$

\title{
JAK BADAĆ MURALE Z PERSPEKTYWY SOCJOLOGICZNEJ? PRZYKŁAD ŁODZI
}

\begin{abstract}
Piotr Mikołaj Statucki, Jak badać murale z perspektywy socjologicznej? Przykład Łodzi [How

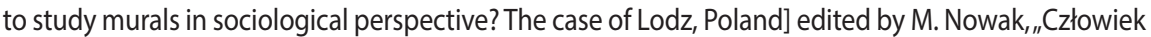
i Społeczeństwo" vol. XLVIII: Kuchnia badań miejskich. Studia na temat praktyki empirycznej badaczy miasta [A backstage of urban research. Studies on the empirical practices of city research scientists], Poznań 2019, pp. 107-122, Adam Mickiewicz University. ISSN 0239-3271.
\end{abstract}

The article explores the study of murals from the point of view of sociology and shows its application, taking the city of Lodz as an example. The proposed perspective is divided into three, partly overlapping sections: artistic, management and organizational areas. It is an attempt to present the methods used in the researches on murals and test them adopting the said division. The purpose of the text includes presenting how murals are perceived by different groups - viewers, art institutions, local media and city government. The research draws attention to the question of maintaining a balance between quantity and quality of art in public space.

Piotr Mikołaj Statucki, student, Uniwersytet Łódzki, Instytut Socjologii, ul. Rewolucji 1905 r. 41, 90-214 Łódź, piotr.statucki@unilodz.eu

\section{Wprowadzenie}

Sztuka ulicy szturmem podbija ściany polskich miast ${ }^{1}$, zyskała uznanie zarówno w masowym odbiorze, jak i w obiegu artystycznym. Jednym z przejawów

${ }^{1}$ Dzięki takim inicjatywom jak Rurales trafia także na wieś. Określenie „sztuka miejska” wydaje się w tym przypadku niefortunne. Dlatego skłaniam się ku pojęciu „sztuka ulicy”, zdając sobie sprawę i z jego ograniczeń. 
tego zainteresowania jest zwiększenie popularności murali, które na świecie przypadło na przełom XX i XXI w., a w Polsce nastąpiło około 2010 r. (Dymna i Rutkiewicz, 2012: 28). Z tego powodu kwestie związane z tym medium są, jak się zdaje, wciąż niewystarczająco rozpoznane. Problematyką murali, czy szerzej - street artu², zajmują się przedstawiciele różnych nauk humanistycznych i społecznych, przyczyniając się do pełniejszego zrozumienia badanego problemu. Niniejszy artykuł na przykładzie Łodzi pokazuje, z jakich punktów widzenia murale może analizować socjolog. Murale można badać z perspektywy socjologii sztuki, jako przedmiot wyrazu artystycznego i percepcji sztuki, ale też jako medium pośredniczące między nadawcami i odbiorcami. Ważne jest również skierowanie uwagi na społeczne funkcjonowanie murali i ich rolę w zarządzaniu i promocji miasta. Prace powstają na zlecenie różnych instytucji, dlatego należy przyjrzeć się też roli decydentów i organizatorów w powstawaniu murali. Obszary artystyczny, miejski i organizacyjny współistnieją i w praktyce często się przenikają, co implikuje konieczność zróżnicowanego metodologicznie podejścia badawczego.

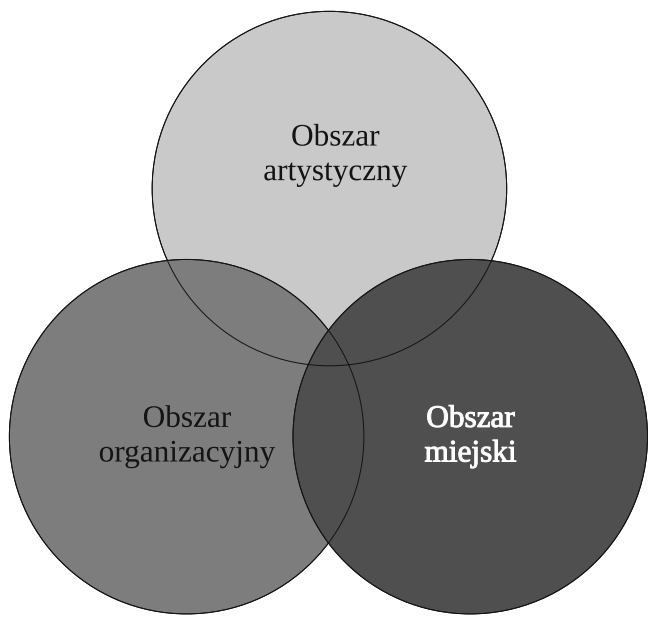

Rysunek 1. Proponowane obszary analizy murali Źródło: opracowanie własne.

Dla obszaru artystycznego wykorzystywane narzędzia badawcze to stosowane przy badaniu opinii na temat murali - wywiad kwestionariuszowy (Jagiełło i in., 2014; Duchowski i in., 2016) i kwestionariusz ankiety (Jażdżewska, 2017), natomiast w badaniu odbioru konkretnych prac słusznym

\footnotetext{
${ }^{2}$ Terminów „sztuka ulicy” i „street art” będę używał w pracy zamiennie.
} 
wyborem jest wywiad swobodny (Gralińska-Toborek i Kazimierska-Jerzyk, 2014). Alternatywą dla jakościowego badania odbioru murali mógłby być wywiad z użyciem fotografii. Dla obszaru miejskiego dobrze sprawdza się analiza danych zastanych, dzięki której zbadać można, jak murale wykorzystywane są w zarządzaniu i promocji miasta. W obszarze organizacyjnym najważniejszy wydaje się wywiad - rozmowa z przedstawicielami organizacji odpowiedzialnych za powstawanie sztuki miejskiej jest istotnym krokiem do zrozumienia roli tego rodzaju instytucji w procesie powstawania murali i zarządzania tymi już obecnymi. Właściwym uzupełnieniem jest prześledzenie działalności tych organizacji na podstawie analizy dostępnych materiałów (analiza danych zastanych, analiza treści).

Przedstawiona w niniejszym opracowaniu propozycja empirycznego badania murali w socjologii dotyczy zatem wspomnianych trzech obszarów i korzysta z części wyżej wymienionych metod. Jest to badanie o charakterze eksploracyjnym, gdyż służy rozpoznaniu problematyki i przetestowaniu podejścia metodologicznego. Analiza obejmuje badania literaturowe, w tym analizę danych zastanych. Wiele informacji przyniosły artykuły prasowe i internetowe, ale też - ważne szczególnie z perspektywy miasta - materiały turystyczne i promocyjne (przewodniki, foldery, mapy, prezentacje, filmy promocyjne). Na potrzeby zbadania obszaru organizacyjnego przeprowadzono dwa wywiady indywidualne. Analiza obszaru artystycznego obejmuje też ankietę internetową na próbie 89 respondentów - narzędzie to pozwoliło na szybkie przebadanie grupy młodych osób i poznanie ich stosunku do murali. Zrezygnowano tu z wywiadów z twórcami murali (artystami) ze względu na trudności organizacyjne (dostęp do respondentów, którzy często są cudzoziemcami), choć początkowo badanie uwzględniało ten aspekt.

\section{Murale jako forma artystyczna i ich odbiór społeczny}

Trudnym zadaniem jest jednoznaczne określenie źródeł murali w historii sztuki, ich korzeni można doszukiwać się w różnych historycznych formach sztuki (Duchowski i in., 2016: 108). Samo słowo „mural” wywodzi się z łacińskiego muralis, co znaczy „znajdujący się na murze”. W ubiegłym wieku murale zaczęły się rozwijać w stronę bliższych nam dziś form. Najistotniejszymi ich ośrodkami w XX w. były: Meksyk, w którym murale miały służyć budzeniu świadomości narodowej po tzw. rewolucji meksykańskiej, oraz Irlandia Północna, gdzie murale pełniły funkcję propagandową w konflikcie między katolikami i protestantami. 
W Polsce murale - głównie reklamowe - zaczęły pojawiać się przed II wojną światową i powstawały licznie w czasach PRL-u. Murale z tego okresu, jak tłumaczy Justyna Mokras-Grabowska (2014: 27), „były rodzajem ogromnych «obwieszczeń», potwierdzających obecność przedsiębiorstwa na rynku. Były także wizytówką artystów plastyków zajmujących się grafiką użytkową, plakatem i malarstwem ściennym”. Powojenne wyburzenia kamienic i fragmentów ulic ułatwiły rozpowszechnienie się murali, mogły mieć też wpływ na współczesną popularność street artu w Łodzi. Tematem łódzkich murali z lat PRL-u zajmuje się Bartosz Stępień, autor poświęconej im monografii (Stępień, 2010) oraz strony internetowej „Łódzkie murale”. Ostatnimi czasy pojawiają się głosy przekonujące o potrzebie odrestaurowania tego rodzaju obiektów znajdujących się w Łodzi (Rakowski-Kłos, 2017), dwie takie grafiki zostały odnowione w ramach budżetu obywatelskiego. Murale reklamowe powstawały w Łodzi również po 1989 r., lecz ich komercyjny charakter zaczął przeważać nad walorami artystycznymi. O łódzkich muralach artystycznych będzie mowa w dalszej części tekstu.

W przypadku murali mamy do czynienia z chaosem pojęciowym. Wielu ekspertów uznaje mural za jeden z przejawów street artu, dla innych taka klasyfikacja budzi wątpliwości ze względu na funkcjonowanie muralu jako sztuki oficjalnej (Gralińska-Toborek i Kazimierska-Jerzyk, 2014: 21; Duchowski i in., 2016: 7). O różnicach między street artem a muralami na korzyść tego pierwszego - pisze Javier Abarca (2016). Według Marcina Rutkiewicza (2013: 13) „murale to w najogólniejszym ujęciu wielkopowierzchniowe malowidła ścienne”. Część ekspertów zgadza się, że murale łączy umiejscowienie w przestrzeni publicznej oraz legalny charakter. Jeśli jednak zagłębić się w różne definicje, natrafiamy na więcej punktów spornych i wyjątków niż rozstrzygnięć. Sami twórcy murali zwracają uwagę na różne cechy tego medium (Duchowski i in., 2016: 13-53). Pojęcia z zakresu sztuki w przestrzeni publicznej są trudne do zdefiniowania, a granice między nimi - nieostre. Pozostaje pogodzić się z tą terminologiczną nieuchwytnością i zaakceptować ją jako cechę sztuki, także sztuki ulicznej.

Zakładając, że murale przynależą do świata sztuki, można dążyć do określenia społecznej tożsamości murali jako formy artystycznej. Punktem wyjścia do rozważań na ten temat jest tekst Krzysztofa Kwaśniewskiego (1984). Według autora celem obranego w pracy podejścia teoretycznego jest „ustalenie socjologicznej tożsamości poszczególnych dziedzin sztuki i kultury przy uwzględnieniu trzech podstawowych członów każdej z nich” (Kwaśniewski, 1984: 75). Wspomniane człony to specyfika danego medium, cechy posługującego się nim środowiska twórczego oraz 
charakterystyka publiczności. Badacz proponuje wyjść od formalnych cech danego środka wyrazu, by następnie określić wpływ jego tożsamości na środowisko twórcze oraz środowisko odbiorców. Kiedy uświadomimy sobie związki między nadawcami, medium i odbiorcami, będziemy mogli traktować analizowany rodzaj sztuki (zgodnie z propozycją Stanisława Ossowskiego) jako ośrodek pewnych nowych stosunków społecznych.

Mural wzbudza przede wszystkim wrażenia niewerbalne, co jest typowe dla form plastycznych. Jego istotą jest przekaz wizualny, choć można go rozpatrywać jako źródło polisensorycznego doświadczenia (Gralińska-Toborek i Kazimierska-Jerzyk, 2014: 55-60; Petri, 2018). Tak jak inne formy działalności artystycznej w przestrzeni publicznej, murale cechuje w zasadzie nieograniczona dostępność. Znajdują się na ogół w miejscach publicznych, na ścianach dobrze eksponowanych. Na tle street artu murale wyróżniają się swoją skalą i artystycznym rozmachem. Ze względu na te cechy są, jak się zdaje, źródłem wrażenia nieuchronnego (Gralińska-Toborek i Kazimierska-Jerzyk, 2014: 33-40). Wyraźnie zaznaczona obecność murali w przestrzeni idzie w parze z ich nietrwałością w czasie. W charakter muralu wpisana jest ulotność - ściany z czasem niszczeją, kolory płowieją, zdarza się, że murale są zamalowywane.

Dzięki znacznej dostępności i zauważalności mural jest dla twórcy atrakcyjnym środkiem ekspresji. W przeciwieństwie do hermetycznego, anonimowego dla osób spoza otoczenia, środowiska writerów twórcy murali zyskują prestiż również poza swoim gronem. Ci najbardziej uznani wykonują prace na całym świecie. Tworzenie murali w różnych miejscach, których artysta często nie ma okazji poznać dokładniej, może być czynnikiem utrudniającym dopasowanie prac do otoczenia. Wydaje się, że twórcom street artu, w tym murali, zależy na wypracowaniu indywidualnego, rozpoznawalnego stylu. Twórcy murali na ogół spełniają się także w innych dziedzinach sztuki i kultury, stąd trudno mówić o jakiejś odrębnej tożsamości muralisty (Duchowski i in., 2016: 15-18).

Powszechna obecność murali w mieście daje mieszkańcom okazję do swobodnego doświadczania sztuki, może wytrącać z codziennej rutyny. Wszyscy zainteresowani mają możliwość obserwowania artysty przy pracy, co byłoby trudne w przypadku nieoficjalnych form street artu i nie jest też oczywiste dla innych gatunków sztuki. Członkowie lokalnej społeczności wchodzą $\mathrm{w}$ interakcje z artystami, bywają też angażowani w samo powstawanie muralu ${ }^{3}$

\footnotetext{
${ }^{3}$ Artyści mogą na różne sposoby włączać mieszkańców do swoich poczynań. Przykładem może być Guido van Helten: fotografowane w odwiedzanym miejscu osoby stają się bohaterami jego prac.
} 
(Modnicka i in., 2016). Wyniki badań społecznych pokazują, że mimo wysokiej akceptacji murali mieszkańcy miast wiedzą niewiele o pracach i ich twórcach (Gralińska-Toborek i Kazimierska-Jerzyk, 2014: 129-159; Duchowski i in., 2016: 90-105). Dla większości osób murale, oprócz niesionej wartości artystycznej, stanowią głównie formę estetyzacji przestrzeni miejskiej. Wśród osób zamieszkujących „ozdobiony” budynek i w jego sąsiedztwie mural może być źródłem tworzenia się nowej tożsamości i być traktowany jako dobro wspólne, pobudzając do dbałości o najbliższą przestrzeń. Odbiór murali wykracza przy tym poza miejsce ich wykonania - przenosi się do Internetu, gdzie udokumentowane prace są rozpowszechniane. Murale są wdzięcznym obiektem fotograficznym, a ich popularność potwierdza np. obecność zdjęć przedstawiających łódzkie murale na Instagramie (Zasina, 2018). Wydaje się jednak, że odbiór sztuki miejskiej za pośrednictwem Internetu nie zastąpi bezpośredniego doświadczenia (Gralińska-Toborek, 2017). Javier Abarca (2016: 66-67) argumentuje, że murale prezentują się na fotografiach lepiej niż inne, bardziej zależne od kontekstu, formy street artu.

Jak pisał Kwaśniewski (1984: 82), określona zgodnie z postawionymi wymaganiami „tożsamość społeczna danej dziedziny sztuki, względnie autonomizującego się w sztukę środka jej transmisji stanowić może pewniejszą podstawę do określenia jej uwarunkowań makrospołecznych, na przykład klasowych, wskazujących, przez kogo i w czyim interesie funkcjonuje owa tożsamość”. Rola murali na poziomie makro jest niejednoznaczna. Zgodnie z paradygmatem miasta kreatywnego murale stają się elementem marketingu, przez co służą klasom wyższym (władzom miasta, inwestorom, właścicielom firm), budując wartość symboliczną i ekonomiczną miasta (Andron, 2018). Z drugiej strony przybliżają sztukę osobom z różnych grup społecznych, również tym, które rzadko mają z nią kontakt w innych okolicznościach.

Przykładem badania opinii na temat murali jest przeprowadzona w czerwcu 2019 r. ankieta internetowa pt. „Opinia studentów na temat murali”, w której wzięło udział 89 studentów różnych kierunków na Uniwersytecie Łódzkim. Badanie pokazało, że skojarzenia studentów z muralami wiążą się przede wszystkim z perspektywą sztuki oraz miasta. Studenci z reguły utożsamiają murale ze sztuką, podobnie jak rozmówcy w badaniu Agnieszki Gralińskiej-Toborek i Wioletty Kazimierskiej-Jerzyk (2014: 140). W oczach respondentów murale pełnią przede wszystkim funkcję estetyczną, upiększając przestrzeń miejską, oraz artystyczną, będąc formą ekspresji twórcy i stwarzając okazję do kontaktu ze sztuką. Dla wielu studentów ważna jest rola mieszkańców, ekspertów i władz miasta na wstępnych 


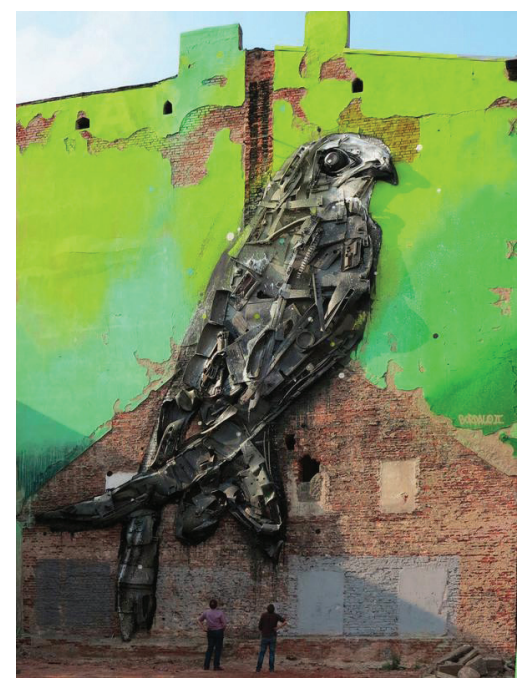

Bordalo II, Apus Apus

6 wskazań

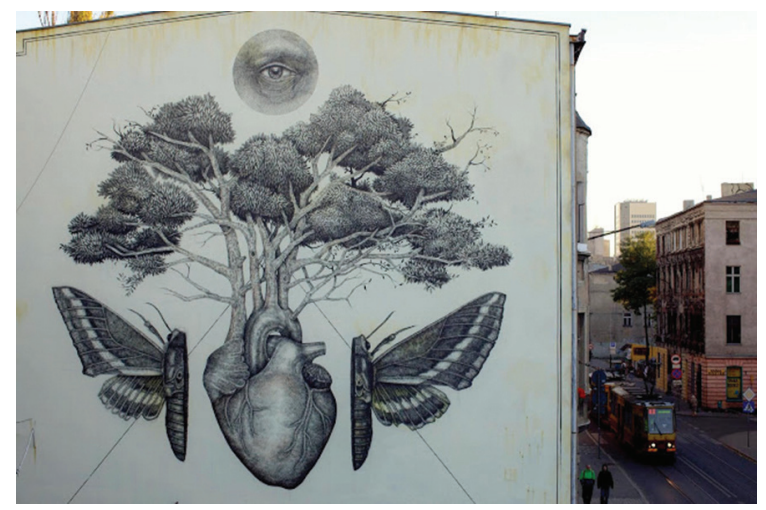

Alexis Diaz, Sentir (Czuć)

5 wskazań

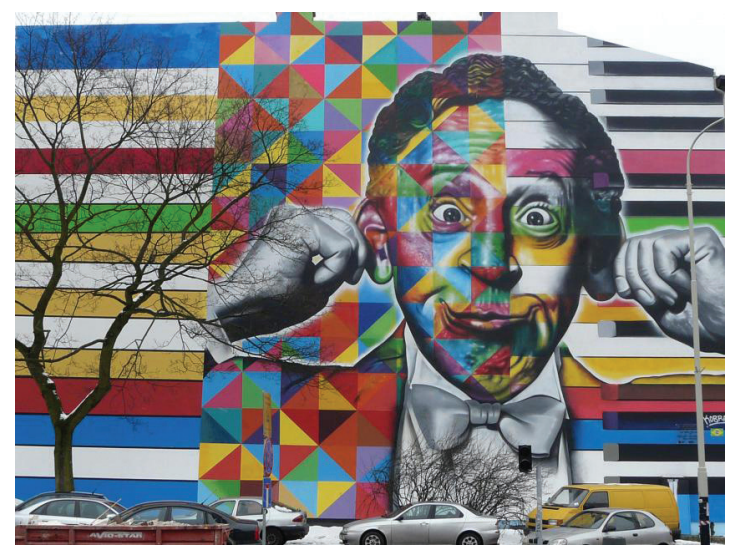

Eduardo Kobra, Rubinstein 4 wskazania Rysunek 2. Najczęściej wskazywane ulubione łódzkie murale Źródło: opracowanie własne na podstawie Urban Forms, 2019; Levy, 2015. 
etapach realizacji projektu, takich jak wybór miejsca przeznaczonego na pracę oraz decyzja co do jej treści i formy. W tych kwestiach odpowiedzi respondentów układają się podobnie jak we wcześniejszym badaniu przeprowadzonym w Łodzi (Jagiełło i in., 2014). Badani uznają murale za atrakcję turystyczną Łodzi albo widzą w nich taki potencjał. Większość studentów uważa spacer szlakiem murali za atrakcyjne wydarzenie i byłaby zainteresowana wzięciem w nim udziału. Na podstawie pytań o preferowane motywy i ulubione prace studentów można dojść do wniosku, że mają oni dość różnorodne upodobania. Niemal połowa respondentów ma w Łodzi swój ulubiony mural - rysunek 2 prezentuje prace najliczniej pojawiające się w odpowiedziach.

\section{Murale a zarządzenie i promocja miasta}

Murale budzą zainteresowanie szerokiej grupy odbiorców, są więc też atrakcyjnym tematem dla mediów, które na bieżąco informują o powstawaniu nowych murali w mieście. Łódzkie prace są licznie prezentowane w polskich mediach: na stronach internetowych, w czasopismach i stacjach telewizyjnych. Wieści o łódzkich muralach wykraczają poza Polskę - sztuka ulicy jest jednym z ważnych elementów promocji miasta za granicą. W 2013 r. stacja CNN przygotowała i wyemitowała dokument o łódzkich muralach (Witkowska, 2013). W podsumowaniu tegoż roku za miarę sukcesu uznano ekwiwalent reklamowy w wysokości 2,5 miliona złotych, który miała uzyskać Łódź dzięki przekazom medialnym poświęconym muralom z Galerii Urban Forms. W 2014 r. ABC News uznała Festiwal Urban Forms za jedno z ciekawszych europejskich wydarzeń kulturalnych, a portal poświęcony sztukom wizualnym i designowi, Bored Panda, umieścił Łódź na drugim miejscu w rankingu dwudziestu światowych centrów sztuki miejskiej (Zuch, 2014). Łódzka sztuka ulicy pojawia się na wielu portalach internetowych, w tym tych poświęconych street artowi czy turystyce. Szerszej analizy obecności łódzkich murali na obcojęzycznych stronach internetowych podjęła się Iwona Jażdżewska (2017: 54-55).

Istotny wydaje się wpływ popularności murali na aspekt turystyczny. Jak zauważa Mokras-Grabowska (2014: 29), wraz z muralami pojawia się „nowa przestrzeń turystyczna, wyróżniająca miasto, będąca symbolem nowoczesności, mody, wzbogacenia miasta w warstwie materialnej czy w końcu nawet podniesienia statusu miasta”. Autorka, na przykładzie 
Łodzi, pisze o wzbogacaniu i poszerzaniu turystycznej przestrzeni miasta. W literaturze można znaleźć wzmiankę o turystyce murali czy turystyce graffiti, której głównym celem jest poznanie sztuki miejskiej (Niemczyk i Paliś, 2017). Należy ona do kategorii turystyki sztuk plastycznych. Agata Niemczyk i Beata Paliś na podstawie badań przeprowadzanych z ekspertami i odbiorcami sztuki ulicznej wnioskują, że mural stanowi atrakcję dla zwiedzających miasto i może być narzędziem jego promocji. Badaczki przewidują rosnące znaczenie murali jako atrakcji turystycznej.

Lokalne media bywają jednak sceptyczne w ocenie murali. Część dziennikarzy, ekspertów i twórców zwraca uwagę na przesycenie nimi przestrzeni miasta. W tekstach często pojawia się niedawno ukute pojęcie: muraloza (Sakosik, 2016). Inne krytyczne argumenty dotyczą m.in.: braku partycypacji mieszkańców w procesie powstawania murali, zredukowania roli murali do funkcji estetycznej, niezadowalającej jakości prac czy ich niedopasowania do otoczenia architektonicznego.

Powyższe zarzuty nie pozostają bez odpowiedzi. Teresa Latuszewska-Syrda zauważa, że teza o zbyt dużej liczbie murali w Łodzi nie została poparta żadnymi badaniami, z kolei Agnieszka Gralińska-Toborek twierdzi, iż „ta sztuka wymrze sama, dopiero jak miasto będzie na tyle ładne, że nie będziemy już potrzebować murali do tuszowania jego mankamentów" (Wesołowski, 2017). Argument o niezaangażowaniu mieszkańców w powstawanie i funkcjonowanie w przestrzeni murali można odpierać, wskazując na wyniki badań społecznych oraz formy aktywności zorientowane na mieszkańców. Argument o ograniczeniu zadania murali do estetyzacji przestrzeni jest odpierany na dwa sposoby. Po pierwsze, wskazuje się, że przestrzeń Łodzi przed dziesięcioma laty potrzebowała zmiany i ożywienia, a w związku z tym dążenie do jej upiększania było właściwą drogą. Po drugie, mieszkańcy miasta nie dbają wyłącznie o estetykę - murale zwracają uwagę odbiorców kunsztem wykonania i zachęcają do refleksji. Kwestia jakości prac może być sporna - rosnącej liczbie zlecanych murali nie zawsze towarzyszy dbałość o wysoki poziom artystyczny. Murale nie zawsze są też dopasowane do przestrzeni, w której funkcjonują. Jak w 2011 r. opowiadał Michał Bieżyński, „artyści tworzący w przestrzeni miejskiej dzielą się na dwie kategorie. Jedni korzystają z otoczenia, inspirują się detalem, fakturą. Drudzy tworzą niezależnie od przestrzeni, w której się znajdują” (Bujalski, 2011). Tego rodzaju kwestie, nietracące do dziś na aktualności, są oczywiste dla osób odpowiedzialnych za wykonywanie murali, których pracy należy poświęcić w tym miejscu więcej uwagi. 


\section{Rola lokalnych organizacji w powstawaniu murali}

Źródłem cennych informacji stały się wywiady swobodne z Teresą Latuszewską-Syrdą z Fundacji Urban Forms oraz Michałem Bieżyńskim z Łódzkiego Centrum Wydarzeń. Na ich podstawie można zrekonstruować ogólny proces powstawania muralu i związane z nim wyzwania organizacyjne.

Pierwszym krokiem jest znalezienie odpowiedniej ściany przeznaczonej na wykonanie muralu. Organizator kontaktuje się z artystą i przesyła mu fotografie przestrzeni, w której miałby znaleźć się nowy obiekt. Po ustaleniu warunków pracy artysta przesyła projekt - zdarza się, że powstaje on dopiero na miejscu, ale jest to rzadko spotykane rozwiązanie. Strona organizująca przygotowuje potrzebne do pracy narzędzia, farby, podnośnik. Artysta ma również zapewniony transport, hotel i wyżywienie. Wykonywanie muralu trwa średnio od 7 do 12 dni, zależnie od wielkości ściany, wybranej techniki oraz stopnia zaawansowania projektu. Czynniki te mają też wpływ na koszt powstania muralu, który waha się zwykle w granicach od kilkunastu do 40 tysięcy złotych. Nowa praca jest promowana przede wszystkim w Internecie, w mediach społecznościowych organizatora oraz, pośrednio, na portalach zajmujących się street artem.

Droga prowadząca do powstania muralu w konkretnych przypadkach może wyglądać nieco inaczej, zależnie od zleceniodawcy. W przypadku Fundacji Urban Forms proces ten zmieniał się wraz z upływem czasu. Rozwój i wzrost popularności galerii murali wpływa choćby na łatwość w pozyskiwaniu do współpracy artystów, którzy sami zgłaszają się z chęcią wykonania muralu w Łodzi.

Fundacja Urban Forms jest najistotniejszą organizacją odpowiedzialną za powstawanie w Łodzi murali. Jej współzałożycielką i prezes jest Teresa Latuszewska-Syrda. Korzeni Fundacji można się doszukiwać w festiwalu Outline Colour Festival, związanym z kulturą graffiti i hip-hopu. Pierwsza edycja festiwalu była zorganizowana w 2008 r. przez Wojciecha Paszkowskiego oraz Latuszewską-Syrdę (Frąckiewicz, 2015: 213). W tym samym roku założyła ona Fundację Wspierania Sztuki Ulicy „Outline”. W Fundacji zrodziła się koncepcja galerii murali w centrum Łodzi, nazwana ostatecznie Galerią Urban Forms. Organizacja działa pod nazwą Fundacji Urban Forms od 2011 r. (Gralińska-Toborek i Kazimierska-Jerzyk, 2014: 5), w tym też roku zapoczątkowała swój festiwal. 
Początkowym zamysłem towarzyszącym założycielom Fundacji było zaproszenie do Łodzi najsłynniejszych twórców murali - ich międzynarodowa sława miała przekonać decydentów do sfinansowania planowanych działań (Frąckiewicz, 2015: 214). Idea galerii murali z czasem znalazła uznanie wśród miejskich urzędników. W Łodzi zaczęli tworzyć znani artyści z całego świata. Od czasu powstania Fundacja zmieniła swoje podejście w Łodzi wiele prac wykonali też nieznani szerzej twórcy oraz doceniani polscy artyści. Tak bogaty przegląd autorów składa się na atrakcyjny i zróżnicowany zbiór prac. Obecnie w Łodzi znajduje się ponad osiemdziesiąt murali będących częścią Galerii.

Za jedno z głównych osiągnięć Latuszewska-Syrda uznaje właśnie zgromadzenie licznego zasobu prac i uczynienie z łódzkich murali silnej marki, cenionej także w środowisku związanym ze street artem. Kolejnym ważnym dla Fundacji dokonaniem jest bieżąca analiza własnych poczynań i ich rezultatów oraz dostosowywanie kolejnych kroków do potrzeb mieszkańców miasta. Fundacja, poza projektami artystycznymi, inicjuje badania naukowe, warsztaty edukacyjne, spacery czy spotkania.

Z początku Fundacja Urban Forms działała przy wsparciu Urzędu Miasta Łodzi, otrzymując zgodę na wykonanie murali na budynkach należących do miasta oraz wsparcie finansowe. Zmianę w relacjach między instytucjami zwiastowało powstanie Łódzkiego Centrum Wydarzeń oraz utworzenie w jego ramach drugiego festiwalu sztuki miejskiej, o którym mowa dalej. W 2017 r. decyzją Biura Miejskiego Konserwatora Zabytków zabroniono wykonywania murali artystycznych na terenie Parku Kulturowego ulicy Piotrkowskiej, mających powstać tam w ramach Festiwalu Łódź Czterech Kultur (Wesołowski, 2017). Od tego czasu sytuacja finansowa Fundacji pogorszyła się, co przekłada się na ograniczenie powstawania nowych murali czy utrudnioną organizację wycieczek szlakiem tych już istniejących.

Wspomniane Łódzkie Centrum Wydarzeń jest samorządową instytucją kultury powstałą w 2015 r. Jego głównym zadaniem jest „organizowanie przedsięwzięć artystycznych, kulturalnych i rozrywkowych o charakterze lokalnym, krajowym i międzynarodowym” (Rada Miejska w Łodzi, 2015). Jednym z obszarów działalności Centrum jest sztuka miejska. W Łódzkim Centrum Wydarzeń odpowiada za nią, jako kurator ds. sztuki w przestrzeni miejskiej, Michał Bieżyński. Wcześniej należał on do Fundacji Urban Forms - jest jej współzałożycielem i pełnił tam funkcję dyrektora artystycznego. Dzięki Łódzkiemu Centrum Wydarzeń powstało w Łodzi kilka nowych murali, ale instytucja przybliża mieszkańcom miasta różne formy 
street artu. „Sześć lat temu razem z Fundacją Urban Forms rozpoczęliśmy projekt zakładający stworzenie galerii wielkoformatowych obrazów. Dziś wydaje mi się, że ta misja została spełniona” - mówił w 2015 r. Bieżyński. „Miasto jest już nasycone pracami. Mamy ponad 50 obrazów. Ten projekt jest na ukończeniu i czas najwyższy pokazać łodzianom inne formy artystyczne” (Bujalski, 2015).

W 2015 r. zaskoczenie mógł budzić fakt, że instytucja postanowiła zorganizować własny festiwal murali - obok tego prowadzonego przez Fundację Urban Forms. Fundacja, planując kolejną edycję festiwalu, „spodziewała się dofinansowania od miasta na dotychczasowym poziomie ok. 200 tys. zł (co roku składa wniosek o dotację), a otrzymała zaledwie 52 tys. zł. Tymczasem Łódzkie Centrum Wydarzeń na swój festiwal dostało 120 tys.” (Kalejdoskop, 2015). Widać, że już w tamtym czasie Urząd Miasta zmienił swoje podejście do Fundacji, nie wybrzmiewała jednak wówczas tak wyraźnie kwestia przesycenia krajobrazu miasta muralami.

Dla prześledzenia procesu powstawania murali w Łodzi i lepszego uświadomienia sobie skali działań wyżej opisanych instytucji warto wykorzystać informacje dotyczące liczby murali tworzonych w kolejnych latach. W pojedynczych przypadkach zaliczenie prac do murali, mimo oficjalnej nazwy projektu lub przyporządkowania na mapie Łódzkiej Organizacji Turystycznej (2019), która była podstawą dla mojego opracowania, może być dyskusyjne. Powracają tu problemy definicyjne - zakwalifikowanie pracy jako muralu może być niekiedy kwestią sporną, głównie ze względu na technikę wykonania lub jej rozmiar. W obliczeniach brałem pod uwagę murale już nieistniejące. Wyróżniłem tu murale zrealizowane przez Fundację Urban Forms i Łódzkie Centrum Wydarzeń. Pozostałe prace powstawały też przy okazji wydarzeń: festiwali (np. Fokus Łódź Biennale, Nowa Klasyka Europy), konkursów (np. Art Mural Challenge, Muralunki), obchodów (np. 800-lecie zakonu dominikanów w Łodzi).

Do 2010 r. w Łodzi powstało niewiele prac. Znaczny wzrost liczby murali miał miejsce w latach 2011 i 2012, gdy Fundacja Urban Forms zaczynała rozwijać swoją Galerię. Kolejny skok nastąpił w roku 2015, a w 2016 padł dotychczasowy rekord - w mieście pojawiły się 24 nowe murale. Od tego czasu widoczna jest tendencja malejąca. Z pewnością znaczenie ma tu rozpowszechnienie tezy o konieczności ograniczenia liczby nowo powstających murali i idąca za nią zmiana miejskiej polityki. Godny odnotowania jest też spory udział podmiotów spoza wyszczególnionej dwójki. W latach 2016-2018 znaczna część murali została bowiem zrealizowana dzięki innym instytucjom lub prywatnej inicjatywie. 
Tabela 1. Powstawanie murali artystycznych w Łodzi do 2018 r.

\begin{tabular}{|l|c|c|c|}
\hline Rok & $\begin{array}{c}\text { Liczba powstałych } \\
\text { murali ogółem }\end{array}$ & $\begin{array}{c}\text { Prace zrealizowane } \\
\text { w ramach Fundacji } \\
\text { Urban Forms }\end{array}$ & $\begin{array}{c}\text { Prace zrealizowane } \\
\text { w ramach Eódzkiego } \\
\text { Centrum Wydarzeń }\end{array}$ \\
\hline $\begin{array}{l}\text { Przed } \\
2010\end{array}$ & 3 & 1 & - \\
\hline 2010 & 5 & 3 & - \\
\hline 2011 & 16 & 12 & - \\
\hline 2012 & 17 & 11 & - \\
\hline 2013 & 10 & 8 & 4 \\
\hline 2014 & 7 & 6 & 4 \\
\hline 2015 & 17 & 12 & 0 \\
\hline 2016 & 24 & 14 & 0 \\
\hline 2017 & 17 & 11 & - \\
\hline 2018 & 13 & 6 & - \\
\hline
\end{tabular}

Źródło: opracowanie własne na podstawie Łódzka Organizacja Turystyczna, 2019.

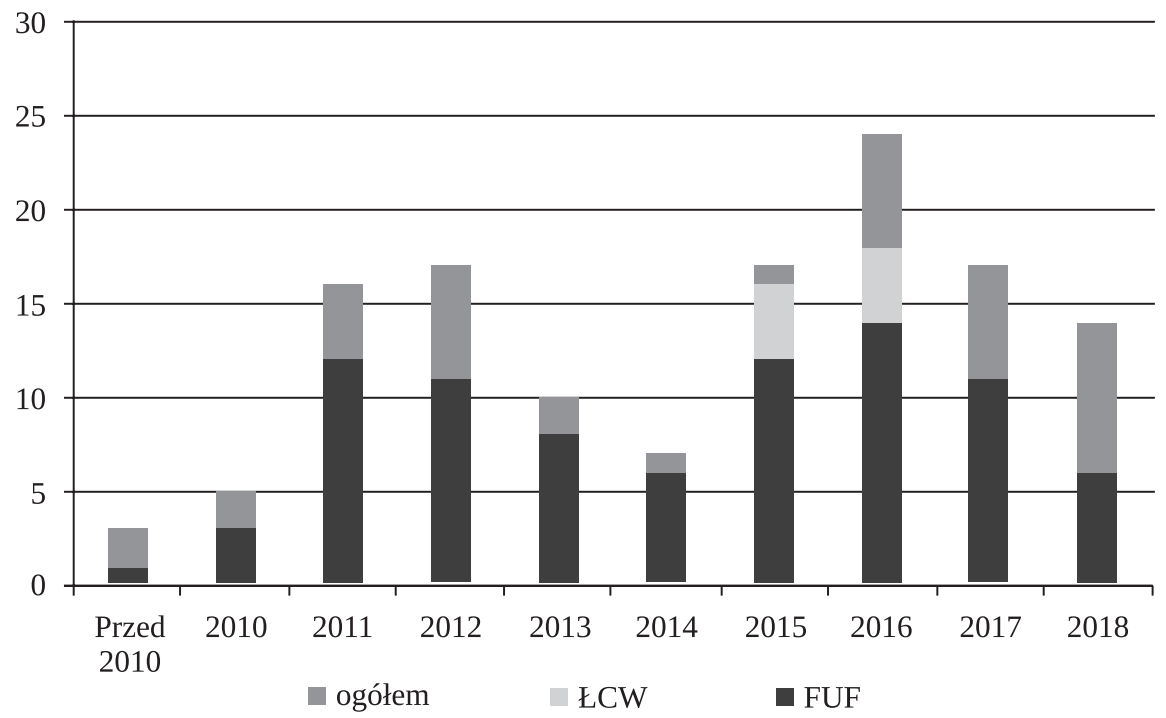

Rysunek 3. Powstawanie murali artystycznych w Łodzi do 2018 r. - wykres Źródło: opracowanie własne na podstawie Łódzka Organizacja Turystyczna, 2019. 


\section{Podsumowanie}

Założeniem towarzyszącym analizie była chęć znalezienia odpowiedzi na pytanie postawione w tytule artykułu. Proponowana odpowiedź nie wiąże się z zestawem konkretnych narzędzi, których wybór zależy od postawionego problemu i podejścia badacza, ale raczej z przedstawieniem perspektywy socjologicznej refleksji nad muralami w trzech obszarach: artystycznym, miejskim i organizacyjnym. Poruszanie się w takich ramach powinno sprzyjać przeprowadzeniu uporządkowanej i gruntownej analizy. Należy przy tym pamiętać o przenikaniu się wymienionych obszarów w przypadku murali. Stąd w tekście artykułu nacisk został położony na empiryczną egzemplifikację przede wszystkim kwestii organizacyjnych i miejskich, z uwzględnieniem społecznego odbioru murali jako formy sztuki.

Murale stanowią bardzo zajmujący, a wciąż niewyczerpany temat. W ciągu ostatnich dziesięciu lat kolekcje tego rodzaju prac pojawiły się w wielu polskich miastach. Badanie na poziomie konkretnego miasta wymaga dobrej znajomości danego ośrodka, jego murali i historii ich powstania, daje tym samym szansę na wnikliwe badanie zjawiska. Kwestią problematyczną, którą ujawniła analiza, jest przesycenie miasta tego typu formą street artu. $\mathrm{Z}$ jednej strony murale są wciąż potrzebne Łodzi - jako forma estetyzacji niewystarczająco zadbanych przestrzeni - i jej mieszkańcom, którzy z aprobatą odnoszą się do tego rodzaju prac. Z drugiej - postuluje się wzięcie odpowiedzialności za przestrzeń publiczną przez decydentów, organizatorów i artystów oraz ograniczenie przyrostu nowych prac. Problem ten zdaje się wciąż wymagać opracowania naukowego, stąd badacze z zakresu nauk społecznych mogą przyczynić się do jego rozstrzygnięcia i proponować odpowiednie rozwiązania.

\section{Literatura}

Abarca, J. (2016). From street art to murals: What have we lost? Street Art \& Urban Creativity Scientific Journal, 2(2), 60-67, https: //doi.org/10.25765/sauc.v2i2.55.

Andron, S. (2018). Selling streetness as experience: The role of street art tours in branding the creative city. The Sociological Review, 66(5), 1036-1057, https://doi. org/10.1177/0038026118771293.

Bujalski, S. (2011). Koniec z szarością. Gazeta Wyborcza - Łódź, 15 lipca, 163, 4. 
Bujalski, S. (2015). Ile murali i od kogo? Gazeta Wyborcza - Łódź, 19 grudnia, 296, 2. Duchowski, M. i in. (2016). Mury. Diagnoza dynamiki środowiska twórców malarstwa monumentalnego. https: //www.nck.pl/badania/raporty/-mury-diagnoza-dynamikisrodowiska-tworcow-malarstwa-monumentalnego\#, dostęp: 12.07.2019.

Dymna, E., Rutkiewicz, M. (2012). Polski street art. Cz. 2: Między anarchiq a galeriq. Warszawa: Carta Blanca.

Frąckiewicz, S. (2015). Żeby było ładnie. Rozmowy o boomie i kryzysie street artu w Polsce. Poznań: Galeria Miejska Arsenał.

Gralińska-Toborek, A., Kazimierska-Jerzyk, W. (2014). Doświadczenie sztuki w przestrzeni miejskiej. Galeria Urban Forms 2011-2013. Łódź: Fundacja Urban Forms.

Gralińska-Toborek, A. (2017). Dual Place of Street Art - the City vs the Internet. Acta Universitatis Lodziensis. Folia Philosophica. Ethica - Aesthetica - Practica, 30, 99-109, http: //dx.doi.org/10.18778/0208-6107.30.07.

Jagiełło, E. i in. (2014). Dialogi wokół murali. Raport z badań opinii przeprowadzonych w ulicznych punktach konsultacyjnych. Łódź: Fundacja Urban Forms. https: //www. urbanforms.org/assets/Uploads/Dialog-wokol-murali-raport.pdf, dostęp: 29.06.2019.

Jażdżewska, I. (2017). Mural jako atrakcja turystyczna w mieście poprzemysłowym przykład Łodzi. Turyzm, 27(2), 45-57, http: //dx.doi.org/10.18778/0867-5856.27.2.04.

Kalejdoskop. Co z muralami? https: //www.e-kalejdoskop.pl/sztuka-a216/co-z-muralamir2036, dostęp: 2.07.2019.

Kwaśniewski, K. (1984). Społeczna tożsamość sztuki, jej dziedzin i środków ich transmisji. Kultura i Społeczeństwo, 3, 73-85.

Levy, R. (2015). Alexis Diaz unveils a new mural in Lodz, Poland. https: //streetartnews. net/2015/10/alexis-diaz-unveils-new-mural-in-lodz.html, dostęp: 29.06.2019.

Łódzka Organizacja Turystyczna. (2019). Mapa łódzkiego streetartu. https: //uml.lodz. pl/files/public/aktualnosci/2019_01/Mapa_Lodzkiego_Streetartu_-_05.01.19.pdf, dostęp: 29.06.2019.

Modnicka, N. i in. (2016). Dialogi wokół murali. Epizody 2016. Łódź: Fundacja Urban Forms. https: //energiamiasta.files.wordpress.com/2016/11/raport_dialogi_2016.pdf, dostęp: 29.06.2019.

Mokras-Grabowska, J. (2014). Przestrzeń turystyczno-artystyczna Łodzi na przykładzie Galerii Urban Forms. Turyzm, 24(2), 25-33. http: //turyzm.pl/artykuly/Pdf_24_2/03_ Mokras_Grabow.pdf, dostęp: 12.07.2019.

Niemczyk, A., Paliś, B. (2017). Mural jako narzędzie promocji turystycznej miasta. Przedsiębiorczość i Zarzq̨dzanie, 18(8/III), 169-181. http: //piz.san.edu.pl/ docs/e-XVIII-8-3.pdf, dostęp: 29.06.2019.

Petri, J. (2018). Touched by a mural: Somatic aspects of urban participation. Art Inquiry, 20,173-184, https: //doi.org/10.26485/AI/2018/20/11.

Rada Miejska w Łodzi. (2015). Załqcznik do uchwały Nr VIII/144/15 Rady Miejskiej w Łodzi z dnia 18 marca 2015 r. http: //archiwum.bip.uml.lodz.pl/_plik.php?plik=uchwaly/ rm/144.PDF, dostęp: 29.06.2019.

Rakowski-Kłos, I. (2017). Czy Łódź potrzebuje starych murali? Gazeta Wyborcza - Łódź, 27 maja, 122, 2.

Rutkiewicz, M. (2013). Murale w Polsce. W: A. Wołodźko (red.), Czytajq̨c mury: książka fotograficzna (ss. 13-15). Gdańsk: Instytut Kultury Miejskiej. 
Sakosik, K. (2016). Łódź stolicą street artu. Gazeta Wyborcza - Łódź, 2 września, 205, 4. Stępień, B. (2010). Łódzkie murale. Niedoceniona grafika użytkowa PRL-u. Łódź: Księży Młyn Dom Wydawniczy.

Urban Forms. (2019). Artyści. https: //www.urbanforms.org/fundacja/artysci, dostęp: 29.06.2019.

Wesołowski, P. (2017). Łódź już nie chce murali. Gazeta Wyborcza - Łódź, 12 sierpnia, 187, 2.

Witkowska, M. (2013). Łódzkie murale w telewizji CNN. Doskonała promocja dla miasta. https: //dzienniklodzki.pl/lodzkie-murale-w-telewizji-cnn-doskonala-promocja-dlamiasta/ar/1048178, dostęp: 7.07.2019.

Zasina, J. (2018). The Instagram image of the city. Insights from Lodz, Poland. Bulletin of Geography. Socio-Economic Series, 42, 213-225, http: //dx.doi.org/10.1515/bog2018-0040.

Zuch, N. (2014). Łódzkie muralopolis. https: //culture.pl/pl/artykul/lodzkie-muralopolis, dostęp: 7.07.2019. 